\title{
From the Desk of Executive Editor
}

This peer reviewed journal is an important assortment of different BanglaJoL articles related to various disciplines of Medical Sciences. It welcomes original articles, review articles, meta-analysis, systematic reviews and case reports from Physicians and Allied Professionals of different Medical Institutions from home and abroad. The website of the journal (www.birdemmedj.org) can be browsed conveniently and the journal can be viewed online through Google and Yahoo. Its ISSN is Print: 2305-3712, Online: 23053720. We have received official registration for the journal from Bangladesh Medical and Dental Council (BMDC). It has also been enrolled to BanglaJoL. One can browse http:/ /banglajol.info/bd/index.php/BIRDEM/index to find out any article by searching the title. Manuscript can now be submitted online. We are also enriched with system to record the number of online readers who have browsed and visited the journal from web site. This is surely very much encouraging to us. In this issue we have increased the number of original articles. This is obviously due to encouraging response o our enthusiastic readers and authors. This proves endorsement or quality, timely publications and fair peer reviewing process of .our journal. In this issue, we have highlighted "Authorship in Scientific Medical Journals" as editorial. We feel tremendously buoyed by our readers participation and their responses from all over the globe. We are very much thankful to the online readers. We also express our pristine appreciation and gratefulness to the authors who bolster our hope immensely and enrich the journal aptly with valuable articles. We eagerly look forward to your valuable advice, suggestions and recommendations in the future.

\section{Prof. Khwaja Nazim Uddin \\ Executive Editor \\ BIRDEM Medical Journal}

